The social construction of ADHD is nourished from very heterogeneous fields that includes various kinds of knowledge, institutions and actors. One of the crucial actor of the field is psychiatrists who are active in the biggest part of research field and who hold the power of diagnosis. Hence, it is important to uncover the discourse of mental health professionals to prevent over diagnosis and overmedication.

\section{P13 IMPACT OF MILITARY SERVICE ON THE PHYSICAL AND MENTAL HEALTH OF UK VETERANS OVER 65}

Hannah Harwood, Victoria Williamson, Sharon Stevelink, Neil Greenberg. King's College London, London, UK

\subsection{6/bmjopen-2019-QHRN.48}

Background The UK veteran population is predominantly elderly; yet little is known about the impact of Armed Forces (AF) service on the wellbeing of older veterans. Some research suggests that service may have negative implications for physical and mental health later in life. Nonetheless, as health problems are also common in older civilians, it is unclear whether veteran health problems are reflective of military service or are a feature of ageing.

Aims/Objectives Aim: To investigate the impact of military service on the health and wellbeing of older UK AF veterans (>65 years) compared to age and gender matched nonveterans.

Methods Qualitative, semi-structured interviews were conducted with $25 \mathrm{UK}$ AF veterans, $10 \mathrm{UK}$ AF veterans with self-reported mental health disorder diagnoses, and 25 nonveterans, all aged over 65 years. A close-companion (e.g. spouse, child, close friend) of all participants were also interviewed to corroborate findings. The data were triangulated and analysed thematically.

Results Three key themes emerged. First, better physical health was reported by veterans and attributed to the high volume of exercise undertaken in the AF. However, veterans also reported more physical health problems (e.g. hearing loss, injuries) due to a lack of protective equipment in the $\mathrm{AF}$ compared to non-veterans. Second, despite health problems, veterans were more reluctant to seek medical treatment than non-veterans, owing to a sense of self-sufficiency instilled during AF service. Finally, veterans developed a greater resilience and self-confidence during service that was carried across the life-course. However, high-levels of workplace trauma exposure appeared to result in psychological problems later in life for some veterans.

Conclusions Military service can have long-lasting positive and negative health effects. Understanding the needs of older veterans is key to ensure effective support services are in place, and that negative effects can be identified and minimised early on in careers.

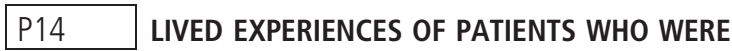 ON MECHANICAL VENTILATION IN AN INDIAN MEDICAL-SURGICAL ICU}

Emi Alias, Sandhya Gupta, Ashima Nehra, Vimi Rewari. All India Institute of Medical Sciences, New Delhi, India

10.1136/bmjopen-2019-QHRN.49
Background Patients on mechanical ventilator in ICU are subjected to various physical and emotional stressors which they may be unable to communicate causing further distress.

Objective To describe the lived in experiences of critically ill patients who were on mechanical ventilation in medical-surgical ICU of a Tertiary care hospital in Delhi, India.

Methods This Phenomenological hermeneutic study included patients above 18 years who were on mechanical ventilator for at least 48 hours in the medical-surgical ICU of a tertiary care hospital between August to November 2017 and fulfilling inclusion criteria. Ethical approval was obtained from institutional ethical committee. The data was collected using indepth interview guide with six patients only out of the twelve enrolled ( $n=6$ dropped out of study). Audio recorded interviews were transcribed and further analyzed by Van Manen's approach.

Results All patients were on ventilator via Endotracheal tube and the duration of mechanical ventilation ranged from 48 hours and $15 \mathrm{~min}$ to 299 hours and $30 \mathrm{~min}$, had no previous experience of ET intubation, mechanical ventilation or ICU stay and interviewed within three days after extubation. The analysis of verbatim revealed emergence of twenty themes and corresponding subthemes which were grouped under four fundamental existentials of human experience which are spatiality, corporeality, temporality and relationality. Most of the patients reported discomfort due to ET tube, problems due to suctioning, impaired communication, altered thirst, hunger and sleep-wake cycle. Two of the patients expressed that they felt more at ease and less embarrassed with staff of same gender. Even comforting words from relatives sometimes caused irritation to patients.

Conclusion There is a need for provision of routine mental health assessment of ICU patients by mental health professionals and interventions to minimize impact of traumatic experiences of patients who're put on mechanical ventilation in order to promote healthy coping patterns.

\section{P15 PARENT PERSPECTIVES ON INTERACTIONS WITH SPEECH AND LANGUAGE THERAPISTS: WHAT FACILITATES ENGAGEMENT}

${ }^{1}$ Rachel Medd, ${ }^{2}$ Tracey Parkin, ${ }^{3}$ Julia Stewart. ${ }^{1}$ Cornwall Partnership Foundation Trust, St Austell, UK; ${ }^{2}$ University of Plymouth, Plymouth, UK; ${ }^{3}$ University of St Mark and St Johns, Plymouth, UK

\subsection{6/bmjopen-2019-QHRN.50}

Background Speech and Language Therapists (SALTs) work closely with parents to engage them in making decisions about therapy, carrying out therapy at home and adapting the way they communicate with their child. The more parents engage in Speech and Language Therapy (SLT) the better the outcomes are for their child. Parent engagement is achieved through the parent-SALT interaction however very little research has investigated this. Research to date focuses on young children receiving early-intervention.

Aims This study explores from the parent perspective how the parent-SALT interaction facilitates parent engagement in SLT for children with long term speech, language and communication needs (SLCN).

Methods The qualitative design adopted an appreciative inquiry approach to guide sampling and interview questions. Parents engaged with SLT services across Cornwall were 